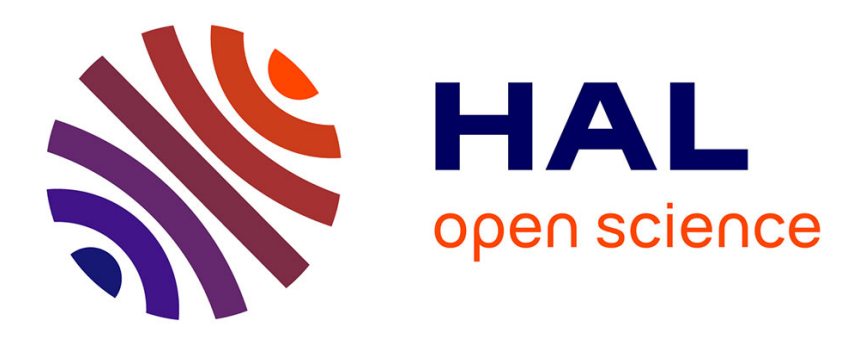

\title{
The use of prior linguistic knowledge in the early stages of L3 acquisition
}

\author{
Rebekah Rast
}

\section{To cite this version:}

Rebekah Rast. The use of prior linguistic knowledge in the early stages of L3 acquisition. International Review of Applied Linguistics in Language Teaching, 2010, 48 (2/3), pp.159-183. hal-00715520

\section{HAL Id: hal-00715520 \\ https://hal.science/hal-00715520}

Submitted on 8 Jul 2012

HAL is a multi-disciplinary open access archive for the deposit and dissemination of scientific research documents, whether they are published or not. The documents may come from teaching and research institutions in France or abroad, or from public or private research centers.
L'archive ouverte pluridisciplinaire HAL, est destinée au dépôt et à la diffusion de documents scientifiques de niveau recherche, publiés ou non, émanant des établissements d'enseignement et de recherche français ou étrangers, des laboratoires publics ou privés. 


\title{
The use of prior linguistic knowledge in the early stages of L3 acquisition ${ }^{1}$
}

\author{
REBEKAH RAST
}

\begin{abstract}
This paper examines cross-linguistic influence in third language acquisition relative to language typology, psychotypology and proficiency level. In particular, it observes how learners make use of their background languages when faced with a language they know little to nothing about. The participants, native French speakers with English as a common L2 (other L2s varied) exposed to Polish (L3) for the very first time, were tested on initial exposure and then at various intervals up to 8 hours. The input provided to our learners from the moment of first exposure was recorded and transcribed. This methodology allowed us to analyze learners' use of prior linguistic knowledge (L1 and other L2s) when performing tasks in a language with low proficiency. Tasks included translating written and spoken sentences, judging grammaticality and rearranging words in sentences. Despite a limited number of participants in each language group, results indicate tendencies. They not only suggest an important role for both typology and psychotypology at this level of proficiency, but they also reveal that even minimal knowledge of a background language can be the source of cross-linguistic influence of various types.
\end{abstract}

\section{Introduction}

Multilinguals have stories and they often go something like this: "I studied a little German in high school in the UK but haven't spoken it in ages. Last week I went to Poland after studying a semester of Polish, and I couldn't believe how German kept popping into my head when I tried to speak Polish". A more un-

1. I sincerely thank Marzena Wątorek, Jean-Yves Dommergues and Clive Perdue for their assistance with data collection and analysis, my two anonymous reviewers for their constructive comments, and Camilla Bardel and Christina Lindqvist for their wonderful support and ability to build bridges. 
usual story is recounted by an English native speaker who knows some Italian and has just returned from studying Spanish in Spain: "I wanted to use my Italian, but I couldn't find it. It was as if my Italian and Spanish were completely separate". What types of processes are at work in these multilingual minds? In the past decade research in multilingualism and third language (L3) acquisition has developed considerably in an attempt to respond to this and related questions. The present article contributes to this discussion by observing how multilinguals work on a new target language (TL) at the very beginning of the acquisition process. In particular, it reports on a study of French native speakers exposed to the Polish language for the very first time. In this study, Polish was not the second language of any of the participants; it was at least the third, if not the fourth, fifth or sixth language learned or studied in terms of chronology. When examining the data for an indication of how our participants processed their Polish input and went on to learn some Polish, we observed that, from the moment of initial exposure, they used aspects of their prior linguistic knowledge to perceive, comprehend and produce Polish. The results of four tasks provide evidence for the important role played by not only the learners' first language (L1) but also their other known languages. Although the knowledge of languages other than one's native language has historically been considered negligible for second language (L2) acquisition, it is now being recognized and accounted for in the study of subsequent language acquisition and in models and theories of second/foreign language acquisition. This article highlights the importance of this new approach to understanding the acquisition of additional languages through analysis of cross-linguistic influence relative to typology, psychotypology, and proficiency level.

\section{Background}

\subsection{L3 acquisition}

The study of L3 acquisition and the influence of prior linguistic knowledge is a fairly new area of investigation (cf. Cenoz et al. 2001; De Angelis 2007; Rast \& Trévisiol 2006; Williams \& Hammarberg 1998). The factors studied in L3 acquisition are numerous: L1 influence, language typology and psychotypology, recency of use, proficiency level of the L2 and the TL, L2 status, the role of Universal Grammar in L3 acquisition, the positive and negative effects of other L2 knowledge in L3 acquisition, length of residence and exposure to the non-native language environment, and order of acquisition (cf. De Angelis [2007] for a recent overview). This article focuses on the role of typology and psychotypology in the acquisition of a novel TL by learners of other L2s at various proficiency levels. With an increase in research in this area has come 
recognition for the need to carefully define our terms. For this study, we adopt Hammarberg's (this issue) recent definition of L3: "In dealing with the linguistic situation of a multilingual, the term third language (L3) refers to a nonnative language which is currently being used or acquired in a situation where the person already has knowledge of one or more L2s in addition to one or more L1s". Most importantly, L3 does not refer to the third language acquired in a linear or chronological sense. We use Hammarberg's term background languages to refer to all languages known to the learner, including the L1, before exposure to the new TL, Polish in this case.

\subsection{The typology/psychotypology distinction}

Numerous L3 acquisition studies have extended Kellerman's (1977, 1979, 1983) psychotypology framework, originally designed for L2 acquisition, to L3 acquisition (cf. Bardel \& Lindqvist 2007; Cenoz 2001; De Angelis 2005; Trévisiol 2006). Kellerman (1979) defines psychotypology as the perceived distance between two languages. Within this perspective, he claims three principal interacting factors that control the use of transfer or cross-linguistic influence by learners: (1) learners' psychological structure of the native language; (2) learners' perception of the distance between their L1 and the TL; (3) learners' knowledge of the TL. To more clearly understand this model, take for example an English native speaker learning Kazakh. The learner has knowledge of English (L1). This knowledge is native and is understood differently by researchers depending on the research paradigm subscribed to. In terms of psychological structure, we seem to agree, nevertheless, that the internal representations in the L1 of an adult who has not experienced L1 attrition are intact at all linguistic levels - phonetic-phonological, morpho-syntactic, semantic, lexical, etc. Our learner of Kazakh would also have some knowledge of Kazakh, even if minimal. According to Kellerman's model, these knowledge stores (English and Kazakh) may interact in interesting ways and this interaction may depend on the learner's own perception of the similarity or distance between any particular form or function in the two languages.

If we are to investigate the role of prior linguistic knowledge in subsequent language acquisition in terms of psychotypology, we need to extend this model to L3 acquisition. To do this, we adapt Kellerman's three principal interacting factors that control the use of cross-linguistic influence (henceforth CLI) in L2 acquisition to the principal interacting factors in L3 acquisition: (1) learners' psychological structure of the L1 as described above; (2a) learners' knowledge and possibly psychological structure of all L2s; (2b) learners' perception of L1-L2 distance as well as L2-TL distance; (3) learners' knowledge of the TL. Note that the perception of L1-L2 and L2-TL distance will need to be 
applied to all L2s known to the learner. In addition, relations between known L2s may be applicable. In this way, we can envisage ongoing interactions between the different knowledge stores of the multilingual speaker/listener (see Figure 1).

When considering the effects of psychotypology on learners' linguistic processes, the question of typology must also be addressed. Ringbom (2007: 8) rightly points out that "genetic relatedness overlaps with perceived similarity". In other words, typology overlaps with psychotypology. He also remarks that identifying relatedness may be more feasible than identifying perceived similarity because the former is objective whereas the latter is not. This point is more controversial than the first. To what extent do typology and psychotypology need to be teased apart? Linguists identify typological similarities and differences by analyzing the languages themselves, whereas language acquisition researchers and psycholinguists identify psychotypology by analyzing human performance, namely language that is perceived, comprehended, parsed and produced. When it comes to language learning and acquisition, the object of interest is what aspects of the TL input the learner converts to intake for subsequent learning.

For several decades, the Contrastive Analysis hypothesis (Lado 1957) influenced our understanding of these processes. According to Lado (1957: 2), "individuals tend to transfer the forms and meanings, and the distribution of forms and meanings of their native language and culture to the foreign language and culture". This transfer could take a positive or negative form. If, for instance, a linguistic feature is related in the L1 and the L2 (from the linguist's perspective), it will be easily assimilated as a result of positive transfer: learning pre-verbal clausal negation in Spanish $(n o+$ verb) should not pose a problem for a native speaker of Portuguese (não + verb) because the word order for this feature is identical in both languages. On the other hand, L2 structures that fail to coincide with corresponding structures of the L1 create difficulty and result in errors due to negative transfer or interference: a native speaker of French $(n e+v e r b+p a s)$ may have difficulty with Spanish negation because the structures in French and Spanish differ. Although there is some truth to this hypothesis, it fails on several accounts. In particular, it fails to recognize that it is the learner's processing of linguistic information that counts, not whether a particular structure described by linguists is attested in the language or not. For this reason, psychotypology needs to be taken into account. We need to observe what learners $d o$ with their TL input and what they perceive in their TL environment as similar or not to other knowledge they have by comparing TL input with learner performance. This is in line with Ringbom's (2007: 5) observation: "The search for similarities is an essential process in learning. The natural procedure in learning something new is to establish a relation between a new proposition or task and what already exists in the mind". 


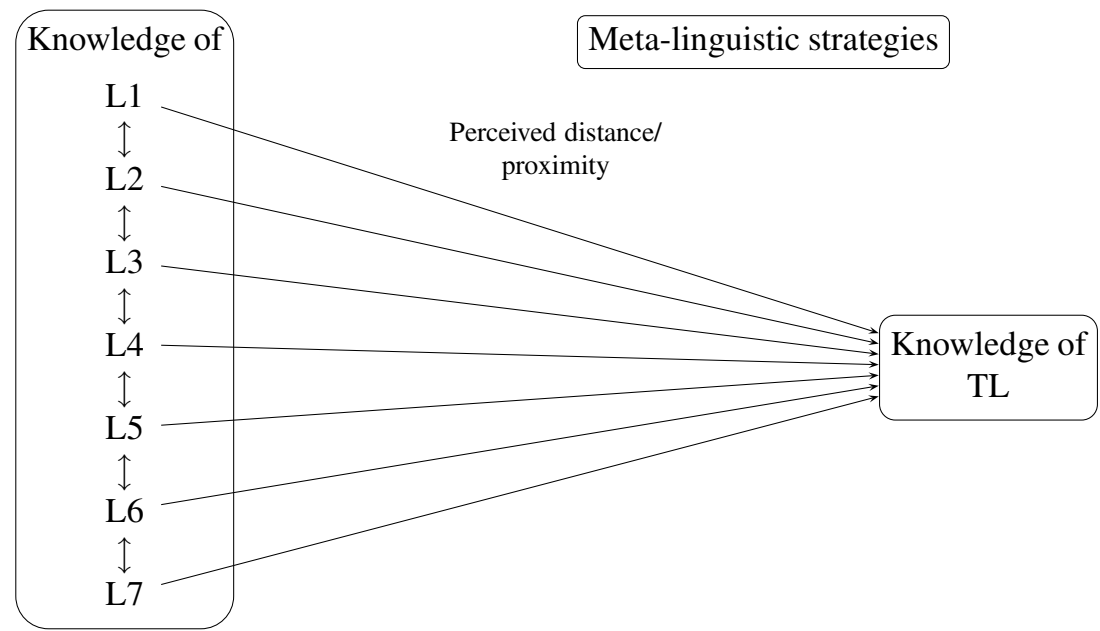

Figure 1. A multilingual learner's psychotypology in L3 acquisition

Research investigating the selective or non-selective nature of language stores in bilinguals can also contribute to this discussion. Research inspired by Dijkstra \& Van Heuven (1998) on the processing of cognates and interlingual homophones and homographs has provided convincing support for a non-selective nature of language stores. Their Bilingual Interaction Activation (BIA) model posits that bilinguals do not store their languages separately, but rather, that interaction between one's languages is a natural process found in bilinguals. The BIA model has recently been applied to L3 acquisition as well with a view to investigating factors that may help multilinguals with their word selection problem during visual word recognition (Dijkstra 2003). De Bot (2004) also proposes an interactive multilingual processing model to account for interaction at the lexical level between multiple languages and even dialects, styles and registers within languages. If we assume the interaction demonstrated by these models within a psychotypology framework, we imagine learners who make use of all linguistic knowledge stores when confronted with a novel TL, as suggested in Figure 1. The quality and quantity of interaction between learners' various background languages and between these languages and the TL may be dependent on the learner's perceived distance (or proximity) between given languages. It follows that meta-linguistic strategies may also take on a more important or different role in L3 than in L2 acquisition. 


\section{Rebekah Rast}

\subsection{Proficiency}

In L2 literature, proficiency level concerns the L2 (TL) only. In L3 literature, the proficiency level of all the learners' L2s, as well as the TL, must be considered. With regard to both proficiency types (other L2s and the TL), empirical evidence has not yet provided a clear picture as to what effect proficiency has on CLI and the source of this CLI. Trévisiol (2006), for example, found that at the beginning stages of L3 acquisition, her Japanese learners of L3 French, who had studied L2 English for 7 to 10 years, relied on both of their background languages (L1 Japanese and L2 English) to produce lexical words, but only on their L1 for functional words. At the intermediate stages, however, learners began to rely on their L2 for functional words. In sum, CLI was prevalent at the beginning and intermediate levels, but the source of CLI shifted with time. Bardel \& Lindqvist (2007) found that their L1 Swedish-L2 English/French/ Spanish learner of Italian did not activate low-proficiency Spanish in her word construction attempts; however, Spanish was very present in her code-switches at the early stages. De Angelis (2008) also shows evidence of an effect of a low proficiency level language on L3 acquisition. It is often assumed that CLI decreases as knowledge of the TL increases (Lindqvist 2009; Williams \& Hammarberg 2009 [1998]), and that the source of CLI is less likely to be a low proficiency language and more likely to be a high proficiency language, as reflected in the fact that background languages other than the L1 are often neglected in second language acquisition (SLA) research. We address these issues in the current study.

\subsection{Initial stages of TL acquisition}

Few studies to date have investigated L3 acquisition at the initial stages. Some work has been conducted on the acquisition of artificial languages (cf. Nayak et al. 1990) and only recently on natural languages (cf. Bardel \& Falk 2007; Carroll 2008; De Angelis 2008; Leung 2005; Rast 2006, 2008). Some of these studies have collected data from the very first moment of contact with the TL and within the first seconds, minutes and hours of subsequent exposure, and in which all TL input was controlled. This methodology allows researchers working on the earliest stages of adult language acquisition to investigate learners' pre-existing systems, including the role that background languages play in a learner's ability to process elements of the new TL. In addition, given that all the TL input is controlled and recorded, such research can tease apart a learner's use of the linguistic environment (TL input) and the use of prior linguistic knowledge.

This article examines, from an L3 acquisition perspective, a selection of data and findings collected from our study of French native speakers exposed to 
Polish with a view to investigating the extent to which learners rely on their L1 versus one of their other languages to perform the TL task at hand. While most research on CLI in L3 acquisition is based on production data, this study contributes to our understanding of CLI for comprehension as well. Furthermore, the majority of studies at the early stages of TL acquisition have focused on the lexicon. This study not only addresses how learners' recognize and/or produce words, but also investigates how they analyze and process certain morpho-syntactic structures of the TL.

\subsection{Hypotheses}

We focus here on three hypotheses that will guide us in our exploration of how learners with knowledge of other L2s proceed to analyze their novel TL input.

(1) The placement of the Polish clausal negator nie. Numerous studies have found that, in early L2 acquisition, learners tend to place the negator in front of that which it negates, thus marking the scope domain of negation independently of the properties of both the L1 and the L2 (cf. Bernini 2000; Clahsen et al. 1983; Giuliano 2004; Hyltenstam 1977; Meisel 1997; Silberstein 2001). We hypothesized that our learners would do likewise in the case of clausal negation during a word order task. If they performed as learners in the above-mentioned studies, they would place the Polish negator in pre-verbal position regardless of the properties of clausal negation in their background languages.

(2) Sensitivity to verbal morphology. One of the defining points of the socalled basic variety (Klein and Perdue 1992), a simple, versatile and highly effective interlanguage system, is that it shows no functional verbal morphology (Perdue 2002). Inspired by these findings based on production data, we sought to investigate whether, on the perceptual level, learners would detect errors of verbal morphology in a written grammaticality judgment test. Given the results from production data, we hypothesized that our learners would not pay attention to Polish verbal morphology regardless of whether or not their background languages showed prominent verbal morphology.

(3) Oral and written sentence comprehension. Little research has been conducted on the effect of other L2s on the comprehension of TL sentences. We hypothesized that when faced with the task of trying to comprehend sentences in oral or written modalities, learners would access the elements of their background languages that share features with the given TL items, even if the languages in contact (the TL and background language in question) are at a low proficiency level. 
Collectively, we expect that if CLI is found to have an effect on participant performance, a background language at low proficiency could be the source of that CLI. The following sections describe the participants of our study, tasks performed and results from an L3 acquisition perspective.

\section{The study}

\subsection{Participants}

Biographical data on the participants of the study were collected by means of a questionnaire intended to identify the native and dominant language(s) of the learners, their previous knowledge of other non-native languages, and their approximate proficiency levels in the respective languages according to their own self-evaluation. All participants had native knowledge of French, intermediate or advanced English, and in most cases, some knowledge of other languages. The additional language knowledge of our participants varied and will be discussed in light of our results. Participant profiles were also similar with respect to gender, age, and other socio-biographical parameters. None had prior knowledge of Polish at the time of the study.

Data reported on here were collected from two distinct types of participants: one group (henceforth learners) attended a specially designed Polish course; the other (henceforth first exposure) comprised participants for whom the language task was their only exposure to Polish. Our learners were students in the French as a Second Language program at the Universite Paris 8, training to become language instructors and fulfilling the requirement to study an unknown language and observe their own acquisition processes. All of our learners were French native speakers; some were raised bilingually and thus had another native language besides French. This will be accounted for in the results section. The first exposure group comprised only French native speakers, also students at the Université Paris 8. We emphasize that these participants were not students of Polish. The task they performed was the only exposure they had to Polish. Their data were used to test hypotheses about language processing at the level of absolute first contact with the TL. Data collected from our learners were used to test hypotheses after a minimal amount of exposure to the TL and to observe the development of specific phenomena over time.

\subsection{Data collection}

The Polish course, taught by a Polish native speaker, was designed to create an environment that simulated as closely as possible that of non-guided learners. The instructor used the communicative approach in the classroom and avoided 
metalanguage. To ensure that the input learners received remained strictly monitored, learners were asked not to consult dictionaries, grammar books, or any outside input for the duration of the data collection period. The class met once a week for two and a half hour sessions over a period of 15 weeks; however, the present study is concerned with the first six class sessions only, that is, the first 8 hours of exposure to Polish, not including testing time. Once the data collection period had ended, the Polish classes continued without the input constraints. The Polish instructor was recorded and her productions were thoroughly transcribed in CHAT format of the CHILDES programs (MacWhinney 2000). This allowed for quantification of word frequencies and occurrences of various word orders. These transcriptions represent the TL input of this study.

Using word order, grammaticality judgment and oral sentence translation tests, we collected data primarily from our group of learners. The first exposure participants performed a written sentence translation test only. The tests are described below in the context of results.

\subsection{Results}

3.3.1. The placement of the Polish clausal negator nie. Learners must have some knowledge of the TL before they can be asked to place a negator in a meaningful way. For this reason, we tested our learners (and not the first exposure participants) after $1 \mathrm{~h} 30$ of Polish instruction on their placement of the clausal negator relative to its verb. We hypothesized that they would perform like learners in the studies cited above, placing the negator in front of the verb regardless of the properties of clausal negation in their background languages. We report on data collected from 14 French native speakers and one FrenchSpanish bilingual after 1 h30 of Polish instruction. Three learners who took the test at $1 \mathrm{~h} 30$ (two French native speakers and the bilingual) had some knowledge of Russian (self-rating of 1 or 2 on a 1-5 scale, with 1 being low and 5 being high proficiency). Some learners also had knowledge of additional languages, German, Spanish, Portuguese and Italian being the most prominent. At periods $3 \mathrm{~h} 30$ and $7 \mathrm{~h} 00$, we report only on data from learners who attended all Polish class sessions, 8 learners in all.

During the word order test, learners were given a context sentence in Polish followed by a sentence in which the Polish words were scrambled. They were asked to put the words in the appropriate order as in the following example:

(1) Tomek mieszka w Paryżu.

'Tomek lives in Paris.'

The words to put in order were: nie - on - lubi - Paryza 'not - he - likes Paris'. Given that we were attempting to capture, with as little TL exposure as 
possible, our learners' preferences for the position of the Polish negator nie relative to its verb, the Polish instructor avoided using negation in the first $1 \mathrm{~h} 30$ of Polish instruction. Scrupulous analysis of the input revealed only seven occurrences of nie for clausal negation in the first $1 \mathrm{~h} 30$ of exposure to Polish. Given this minimal input, when administering the word order test, we explained to the learners that nie is a Polish negator, and we asked them to place it where they felt appropriate. Before discussing results, we will briefly look at negation in the languages of our learners. ${ }^{2}$

In Polish (2) and Russian (3), the clausal negator precedes the finite verb.

(2) Ewa nie idzie do szkoty.

Ewa not goes to school

'Ewa does not go to school.'

(3) Anka ne pišet statej.

Anka not writes articles

'Anka does not write articles.'

Spanish, Portuguese and Italian also have pre-verbal negation. In French, however, the dominant negator pas follows the finite verb as in (4).
(4)
Anne ne
va pas
à l'école.
Anne (weak neg) goes not (strong neg) to school $^{3}$
'Anne does not go to school.'

In English the negator not follows the inflected auxiliary in negative clauses as in (5).

\section{(5) Fred does not understand.}

In simple sentences in German, nicht appears after the finite verb or the auxiliary as in (6).

\section{(6) Ich verstehe nicht. \\ I understand not \\ 'I do not understand.'}

If learners follow the negation pattern of their L1 French, we would expect to see post-verbal negation in their Polish responses. Such a working hypothesis could be confirmed by their knowledge of English given that the English negator also follows the inflected verb; however, it could also create confusion in that the negative particle does not follow the thematic verb as it does

2. Space constraints forego an adequate discussion of negation in the languages of the study. See Rast (2008) for a more in-depth analysis.

3. See Rast (2008: Ch. 3) for a discussion of French negation ne...pas. 


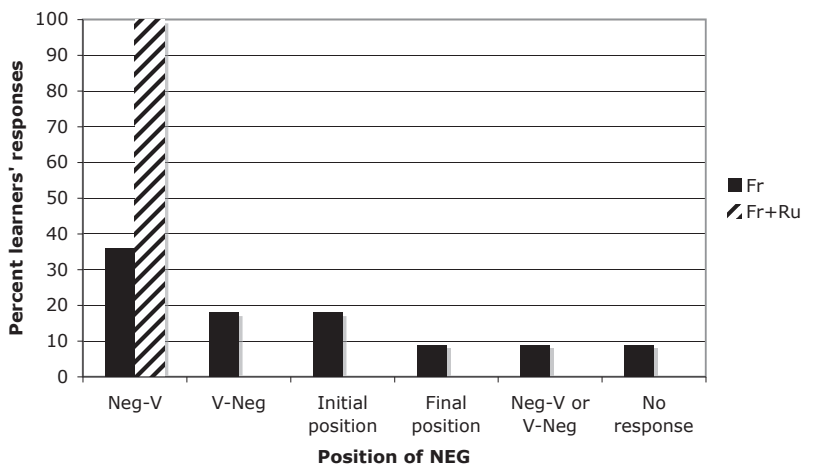

Figure 2. Placement of Polish negator by French speakers with and without knowledge of Russian ( $F r=$ French native speakers with no knowledge of Russian, $n=3 ; F r+R u$ $=$ French native speakers with knowledge of Russian, $n=12$ )

in French simple present tense clauses. If those with knowledge of Russian apply the Russian negator pattern to Polish, we would expect to see pre-verbal negation in their responses. The same would be true for those with L2 Spanish, Portuguese or Italian. German as a source of CLI would likely result in post-verbal negation. Finally, if they place the negator where much research in the past has shown beginning language learners to place negators, we would expect to see pre-verbal negation.

Figure 2 shows the responses of our learners ( $n=15$ for this analysis) after $1 \mathrm{~h} 30$ of exposure to Polish. Three sentences in the test contained the negator. In most cases learners placed the negator in the same position in each of the three sentences. All of those with knowledge of Russian $(n=3)$ placed the negator in pre-verbal position. Those with no knowledge of Russian $(n=12)$ responded in a variety of ways. Pre-verbal position was dominant, but some learners also placed the negator in post-verbal position, or in clause initial or final position, failing to support the hypothesis that learners at the earliest stages of L2 acquisition systematically place the negator in front of that which it negates. These findings comply with those of Bardel (2006), who found both pre- and postverbal placement of the negative particle in L3 Italian and attributed this to the role of the background languages.

If we extend Kellerman's (1983) framework of psychotypology to L3 acquisition as suggested above, such a psychotypology hypothesis predicts that our French native speakers with knowledge of other L2s will rely on the L1 or L2 structure that they perceive as being more similar to the TL structure in question. As our learners with knowledge of Russian all placed the negator in pre-verbal position during the word order task in Polish while only some 
of those without knowledge of Russian did so, we believe that, in addition to other factors, CLI of L2 Russian towards L3 Polish is likely at work.

We proceeded to analyze individual responses of our learners with no knowledge of Russian relative to their knowledge of languages other than their L1:

(1) Learners with knowledge of German $(n=3)$ : all responded with postverbal negation (V-Neg) or with the negator in sentence final position;

(2) Learners with knowledge of Spanish, Portuguese and/or Italian (not including the French-Spanish bilingual) $(n=5)$ : two responded with pre-verbal negation $(\mathrm{Neg}-\mathrm{V})$, two with sentence initial position, and one with a mix of pre- and post-verbal negation.

Although this represents a small participant sample, the results signal a possible tendency, that those with knowledge of German tended to place the negator somewhere after the verb and those with knowledge of Spanish, Portuguese and/or Italian tended to place the negator somewhere before the verb. Although this observation needs further investigation, it suggests that languages other than the L1 and the TL played a role in our learners' placement of the Polish negator. It also suggests that the language triggering CLI was not necessarily typologically related to the TL. Once again, applying the model of psychotypology to this analysis, we propose that learners searched for familiar and similar information in their linguistic stores. Those who found Russian negation in their stores were able to benefit from it. Those without this knowledge may have activated the relevant structure in their other L2s, such as pre-verbal negation in Spanish or Portuguese or post-verbal negation in German, respectively aiding or hindering their placement of the negator in Polish.

Figure 3 reflects the placement of Polish nie, at all three periods, by the 8 French native speakers who attended all class sessions. At Period $7 \mathrm{~h} 00$ our learners responded with the correct Polish word order, Neg-V, in $100 \%$ of the sentences, showing a positive effect of the number of hours of instruction on our learners' ability to correctly place the clausal negator nie in a Polish sentence. Although clear already at Period $3 \mathrm{~h} 30$, the effect is maximal at Period 7h00. It is important to note that we capture the influence of our learners' background languages on their placing of the Polish negator only in this very short period of a few hours. This highlights the importance of collecting data at the true beginning of the TL acquisition process so that sources of CLI in these first hours of exposure can be traced.

3.3.2. Sensitivity to verbal morphology. We administered a series of grammaticality judgment tests to our learners to test their sensitivity to verbal morphology when reading a short paragraph comprised of vocabulary introduced in the Polish course. We hypothesized that learners would pay little to no attention to verbal morphology at this early stage of acquisition. For this phenomenon, 


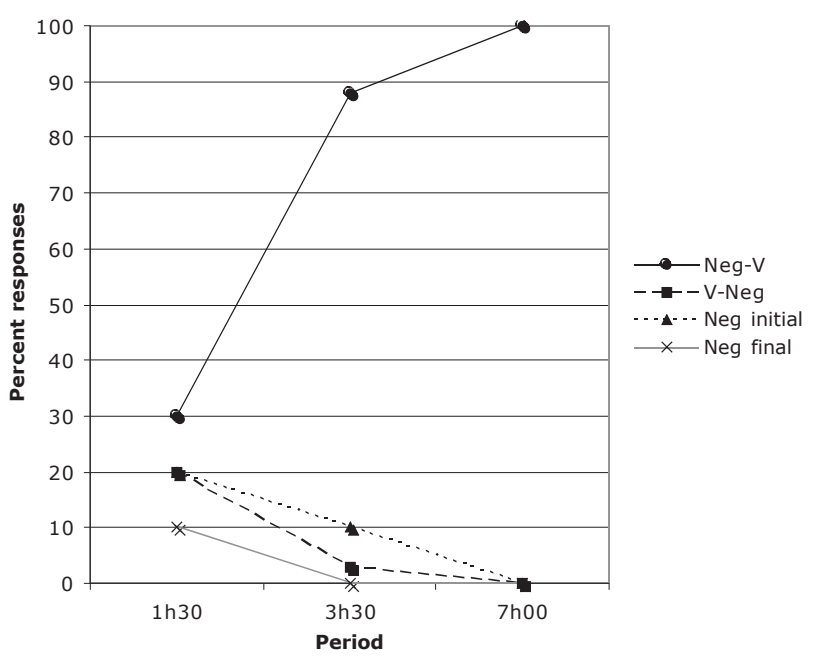

Figure 3. Negation: The evolution of response types from Period 1 h30 to 7 h00 (reproduced here from Rast (2008) with the permission of Multilingual Matters)

we report on data collected from our learners only, in this case the 8 French native speakers who attended all class sessions and the 3 learners with knowledge of Russian (two French native speakers and one French-Spanish bilingual). The tests were administered after 1h30, 3h30 and 7h00 of Polish instruction.

The learners were asked to read the text, find the ungrammatical forms, and correct them. We then asked our learners to translate the Polish text into French to control for their comprehension of the written vocabulary used in these tests. Consider the sentence extracted from the $1 \mathrm{~h} 30$ test:

\section{(7) Mieszkam ona $w$ Chicago.}

(I) live she in Chicago

The marker -am in mieszkam refers to first person singular, whereas the subject ona (she) and the context require the third person singular marker - $a$ as in mieszka. Would learners, after $1 \mathrm{~h} 30$ of Polish exposure, notice the error in morphology? Would they notice errors of this type after $3 \mathrm{~h} 30$ or after $7 \mathrm{~h} 00$ of exposure?

Table 1 shows the number of verbal morphology errors corrected by each of our participants at the three periods. Given the difficulty of computing reliable statistics from a small sample of learners with groups of unequal size, we provide raw data for responses of individual learners. Percentages are given for 
Table 1. Verbal morphology errors corrected during grammaticality judgment tests at periods 1h30, $3 \mathrm{~h} 30$ and $7 \mathrm{~h} 00$ (learners without and with knowledge of Russian). (Partial results appear in Rast (2008) and are reprinted here with the permission of Multilingual Matters.)

\begin{tabular}{|c|c|c|c|}
\hline & $\begin{array}{c}\text { Period } 1 \mathrm{~h} 30 \\
\text { Number of errors } \\
\text { corrected (3 possible) }\end{array}$ & $\begin{array}{c}\text { Period } 3 \mathrm{~h} 30 \\
\text { Number of errors } \\
\text { corrected (3 possible) }\end{array}$ & $\begin{array}{c}\text { Period } 7 \mathrm{~h} 00 \\
\text { Number of errors } \\
\text { corrected (2 possible) }\end{array}$ \\
\hline \multicolumn{4}{|c|}{ Learners without Russian } \\
\hline Dalia & 0 & 0 & 0 \\
\hline Emma & 1 & 3 & 2 \\
\hline Gilles & 2 & 2 & 1 \\
\hline Julie & 0 & 0 & 2 \\
\hline Luc & 0 & 0 & 2 \\
\hline Nadine & 1 & 3 & 2 \\
\hline Sabine & 1 & 1 & 1 \\
\hline Sandra & 2 & 3 & 2 \\
\hline Total & 7 of $24(29 \%)$ & 12 of $24(50 \%)$ & 12 of $16(75 \%)$ \\
\hline \multicolumn{4}{|c|}{ Learners with Russian } \\
\hline Cécile & 0 & 3 & 2 \\
\hline Celia & 2 & 3 & 2 \\
\hline Eva & 3 & 3 & 2 \\
\hline Total & 5 of $9(56 \%)$ & 9 of $9(100 \%)$ & 6 of $6(100 \%)$ \\
\hline
\end{tabular}

total corrections by group (knowledge of Russian or not) and by period (1h30, $3 \mathrm{~h} 30$ and $7 \mathrm{~h} 00$ ) to highlight possible tendencies.

Three observations are worth mentioning here. Firstly, we see the development of our learners' sensitivity to verbal morphology over time. Our learners with no knowledge of Russian moved from $29 \%$ recognition of errors at Period $1 \mathrm{~h} 30$ to $50 \%$ at $3 \mathrm{~h} 30$ to $75 \%$ at $7 \mathrm{~h} 00$. Secondly, taken as a group, the three learners with knowledge of Russian showed little difficulty in performing the task, especially after $3 \mathrm{~h} 30$ of Polish instruction, at which point the three learners found all the errors. This suggests that CLI of a background language other than the L1, even if at a low proficiency level, could have an impact on the learners' ability to notice morphological errors, at least in the case of typologically related languages like Polish and Russian. Thirdly, individual variability is quite evident in these results. Over the three periods, Dalia never finds an error, whereas Emma, Nadine and Sandra appear sensitized to verbal morphology after only $3 \mathrm{~h} 30$ of exposure. Further research will need to confirm these results, but the data presented here indicate that our learners noticed morphological marking to a greater extent than was expected. Finally, our data suggest 
that learners with knowledge of Russian, a language with prominent verbal morphology, not only accessed this knowledge to perform the task of judging verbal morphology errors in Polish, but also benefited from it.

3.3.3. Oral sentence comprehension. To investigate how learners analyze spoken utterances of the TL and to what extent they make use of their background languages to do this, we administered an oral sentence translation test (cf. Klein 1986) to our learners after $1 \mathrm{~h} 30$ of Polish instruction. We report here on data collected from the same learners as those reported on above for verbal morphology, that is, 8 learners of Polish with no knowledge of Russian and 3 learners of Polish with limited knowledge of Russian. We focus here on our learners' translations of two sentences in the test for the benefit of qualitative analysis.

Learners were instructed to listen to each sentence, which they heard twice, and translate it into written French on the response sheet provided. Test items varied with respect to basic constituent word order, the frequency of the lexical items in the Polish input provided during instruction, the transparency of items relative to French (e.g., cognates), and sentence length. ${ }^{4}$ In our analysis of the results, we focus on a comparison between the performance of learners with no knowledge of Russian and that of learners with low proficiency in Russian.

The first sentence analyzed poses a potential challenge for French native speakers as it shows object-verb-subject word order, an unlikely basic constituent word order in their L1. ${ }^{5}$ Those with knowledge of Russian, however, had already been exposed to a variety of constituent word orders given that Russian, like Polish, shows flexible word order, albeit with pragmatic constraints.

Sentence 1. The Polish utterance heard:

$$
\begin{aligned}
& \text { Po polsku mówi ona dobrze. } \\
& \text { En polonais parle elle bien. } \\
& \text { in Polish speaks she well } \\
& \text { 'She speaks Polish well.' }
\end{aligned}
$$

Learners' translations are presented in Table 2 and 3. We respected the spelling, capitalization, and punctuation in the French responses of our learners.

4. For information regarding the effect of these factors, see Rast (2008: Ch. 8)

5. It is important to point out here that we occasionally used a slightly manipulated form of Polish, judged by some Polish native speakers as pragmatically "odd". This was necessary in order to test certain phenomena such as the comprehension of specific elements in Polish utterances relative to a given basic constituent word order. 
174 Rebekah Rast

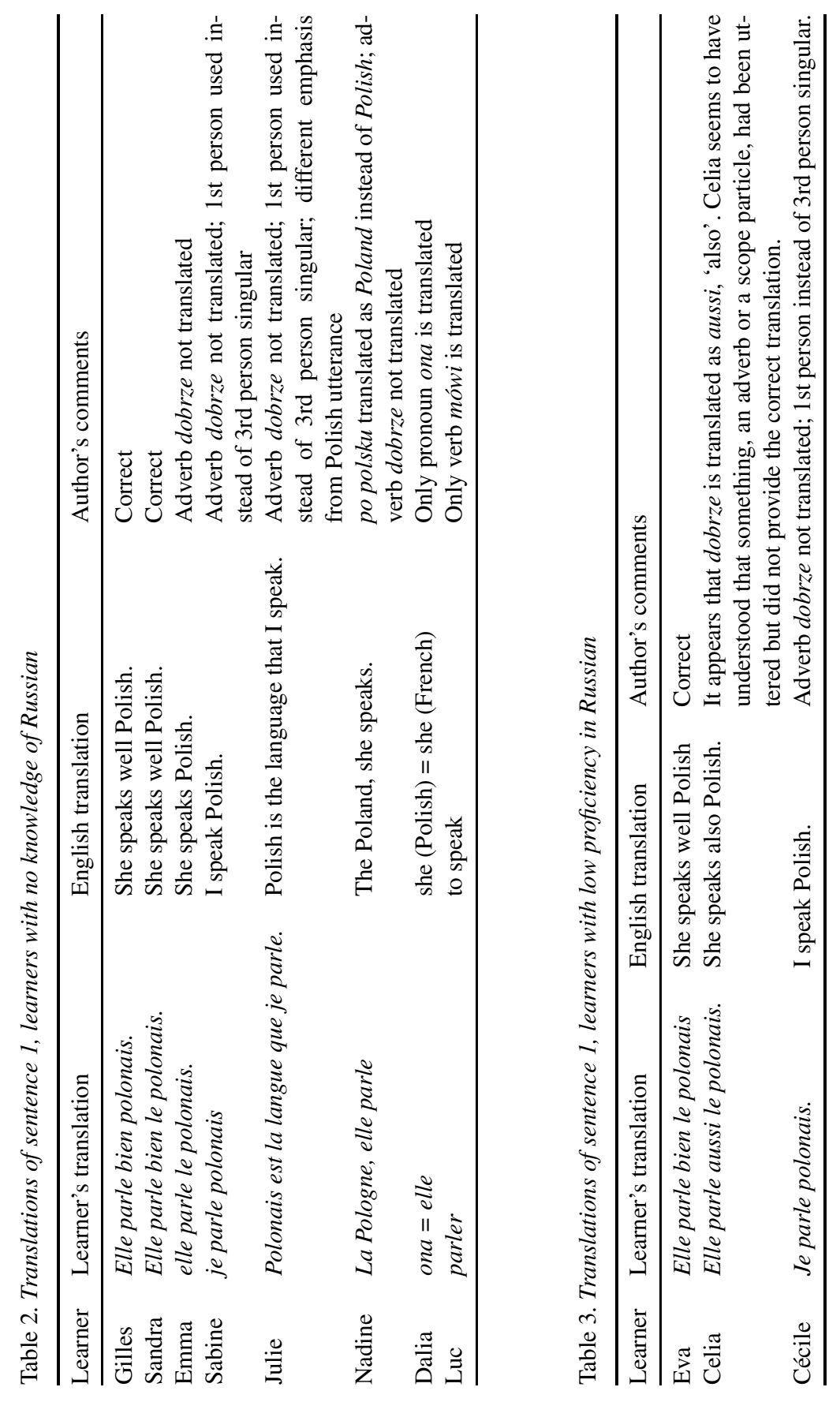


We see in Table 3 that one of our learners with knowledge of Russian, Eva, translated the sentence correctly. Another, Celia, understood all but the adverb dobrze. Finally, Cécile omitted the adverb dobrze and misinterpreted the subject pronoun. All three of these learners showed evidence of comprehending the essential information communicated by the sentence. Turning to our learners with no knowledge of Russian (cf. Table 2), we note that two learners translated the sentence correctly (Gilles and Sandra) and three others showed a comprehension of the essential information (Emma, Sabine and Julie). The remaining three learners, however, understood only discrete elements in the sentence but not the overall meaning. The fact that none of the learners with knowledge of Russian had trouble capturing the essential information communicated by the sentence may indicate a positive effect of knowing some Russian. In contrast, three of the learners without knowledge of Russian showed signs of difficulty. Let us examine the translations of another sentence.

Sentence 2. Although Sentence 2 shows a word order that is more familiar to French native speakers than the order in Sentence 1, it still carries challenges, mostly in length (13 syllables) and in lexical difficulty (minimal transparency with French). The Polish utterance heard:

$$
\begin{aligned}
& \text { Ines nie zna dobrze jezyka polskiego. } \\
& \text { Ines pas connaît bien langue polonaise. } \\
& \text { Ines not know well language Polish } \\
& \text { 'Ines does not know the Polish language well.' }
\end{aligned}
$$

Gilles is the only learner with no knowledge of Russian who grasped the essence of this sentence (cf. Table 4). Looking at his choice of translation equivalents, we observe that he chose the French word parle ('speaks') instead of connaît 'knows', the literal translation of Polish zna, and translated jezyka polskiego 'language Polish' as polonais 'Polish' rather than langue polonaise 'language Polish'. Sandra processed polskiego as Pologne 'Poland' and Emma as Polonaise (Polish nationality, feminine). One learner wrote Ines only, and three supplied no response. For comparison, let us look at how our learners with Russian as a background language fared.

Comparing the translations of the two groups, we observe that Eva (with Russian) and Gilles (without Russian) came the closest to a correct translation. Eva, unlike Gilles, translated zna 'knows' as sait 'knows', revealing her grasp of the literal meaning of zna. In the same way as Gilles, Eva translated jezyka polskiego 'language Polish' as polonais 'Polish' and not langue polonaise 'language Polish'. Celia's response shows that she understood the essence of the sentence, and Cécile, consistently the weakest of this group of three learners, 
Table 4. Translations of sentence 2, learners with no knowledge of Russian

\begin{tabular}{lll}
\hline Learner & Learner's translation & English translation \\
\hline Gilles & Ines ne parle pas bien polonais. & Ines speaks not well Polish. \\
Sandra & Ines ne connait pas la Pologne. & Ines knows not Poland. \\
Emma & $\begin{array}{l}\text { Ines n'est pas Polonaise. } \\
\text { Sabine }\end{array}$ & Ino response) \\
Julie & Ines (?) & \\
Nadine & Ines parle polonais. & Ines speaks Polish. \\
Dalia & (no response) & \\
Luc & (no response) & \\
\hline
\end{tabular}

Table 5. Translations of sentence 2, learners with low proficiency in Russian

\begin{tabular}{lll}
\hline Learner & Learner's translation & English translation \\
\hline Eva & Ines ne sait pas bien parler polonais & Ines knows not well to speak Polish. \\
Celia & Ines ne connait pas le polonais & Ines knows not Polish. \\
Cécile & Ines ... pas ... polonais. & Ines ... not ... Polish. \\
\hline
\end{tabular}

showed partial comprehension. Taken as a whole, they fared better than the learners with no knowledge of Russian.

Once again we acknowledge the small number of participants in this study and recognize that we must remain modest in our conclusions. This said, it is our belief that working on language data such as these provides us with hypotheses that can be tested cross-linguistically in a variety of ways in future research. A comparison between responses of learners with no Russian and those with some Russian suggests that the latter group may have had an easier time translating a Polish sentence into French because of the similarities found between Polish and Russian. To confirm this hypothesis, one would need to identify the features shared by the TL and the specific L2 that may be at the source of the CLI.

3.3.4. Written sentence comprehension. Rast $(2006,2008)$ found that knowledge of specific background languages had an effect on the performance of French native speakers exposed to Polish for the first time during a word translation task in which participants read or listened to isolated Polish words and translated them into French. Those who had some knowledge of Russian were found consistently to show some advantage over the others, and this in spite of the fact that they had only minimal knowledge of Russian and that Russian was the fourth language chronologically speaking for most of them. 
In the current study, we administered a written sentence translation test to our first exposure participants (not our learners this time) to explore the role of background languages in participants' comprehension of words that were not in isolation. Although context can be difficult to provide at first exposure to a novel TL, one would expect that words presented in a coherent text should provide more possibilities for hypothesis formation than words in isolation in that patterns may materialize regardless of whether or not one comprehends the individual components of the TL utterances.

The participants for this task $(n=20)$ were not learners of Polish but rather French native speakers who had had no previous contact with Polish at the onset of the study and were not attending the Polish course. We divided the participants into three language groups:

(1) With knowledge of Russian $(n=7)$;

(2) With knowledge of other Romance languages $(n=8)$;

(3) With knowledge of German $(n=5)$.

Those with Russian rated their proficiency in Russian as a " 1 " on a scale of 1-5 ( 1 being low and 5 being high proficiency) with the exception of one participant who noted the rating of 2 .

Participants were asked to read Polish sentences and to translate what they thought they understood into written French. The sentences were taken from a recording of the first minutes of Polish instruction to our group of learners in an attempt to use the type of language that one might naturally be exposed to when first learning a foreign language. We extracted the first 15 utterances of the transcript and asked our participants to translate them, a total of 102 words. As an example, the first utterance was:

$$
\begin{aligned}
& \text { To jest lekcja jeden } i \text { temat prezentacja. } \\
& \text { Ceci est leçon un et theme présentation. } \\
& \text { this is lesson one and theme introduction } \\
& \text { 'This is the first lesson and the theme is introductions.' }
\end{aligned}
$$

For our analysis, we calculated the number of words that each participant attempted to translate and of these, the number each participant managed to translate correctly. Correct translations were defined as follows: French translations that were semantically related to the Polish test word were considered correct translations regardless of their grammatical composition. For example, the French translation for the Polish word studiuje is il/elle étudie 'he/she studies'; however, we accepted étudier 'to study' and étudiant 'student' as correct translations of studiuje as well. French translations that were not semantically related to the Polish test word were considered incorrect translations. In sum, the attempted translations represent all the attempts at translation, including both correct and incorrect translations, whereas correct translations refer to only those attempts that were semantically related to the Polish test word. 


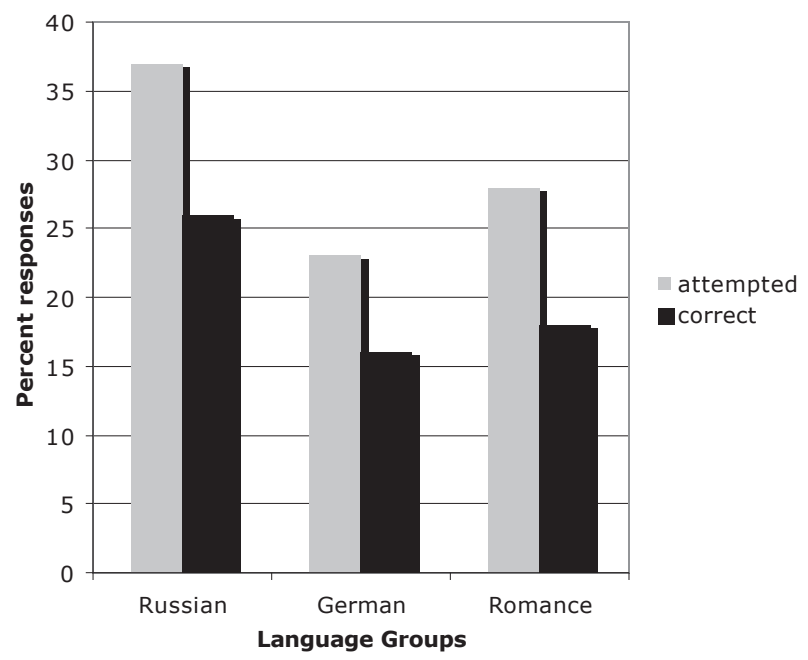

Figure 4. Written sentence comprehension: Attempted and correct translations by language group

We analyzed our participants' responses by means of a one-way ANOVA as shown in Figure 4.

Results showed no main effect of language group for attempted translations (correct and incorrect combined), $F(2,17)=2.972, p=.0782$, n.s. This indicates that members of all language groups attempted to translate sentences to a similar extent. With regard to correct translations, however, results of a oneway ANOVA showed a significant effect of language group on correct translations, $F(2,17)=3.719, p<.05$. A PLSD Fisher showed this effect to be due to the difference between the Russian and German groups only $(p<.05)$. With regard to this task, these results suggest a slight benefit of knowing Russian over German, but not necessarily over Romance languages.

Future research would benefit from similar types of analyses with larger participant groups and more instances of TL words that share formal and/or functional features with words in learners' background languages. In this way we could explore the extent to which learners access specific linguistic information when attempting to comprehend an utterance in the novel TL. A more in-depth comparison of the formal features of the TL word and its equivalent in the learners' background languages is also needed, including cases where the formal features are similar, or even identical, but the functions differ. Rast (2006, 2008) identified several cases of the latter in the data collected from the word translation test described earlier. For example, the Polish word mówi 
'he/she speaks' was translated by almost half of the participants in the study as film or cinéma in French, suggesting activation of their English 'movie', albeit with an unsuccessful outcome. In a similar vein, many participants with knowledge of German translated Polish jeden 'one' as either chaque 'each' or tous 'all', both correct translations of German jeden. These findings were not surprising given that Polish and German show the identical form jeden, and Polish and English show the similar forms mówi and movie (pronounced similarly).

Data collected from the written sentence translation test of the current study also show traces of this word selection process, although the number of occurrences is not as striking, particularly with respect to English. Of the 20 participants, all of whom had knowledge of English, 3 incorrectly translated Polish mówi as film and one as bouge 'move'. Of the 5 participants with knowledge of German, 4 translated jeden as chaque 'each'. What precisely are the processes at work here? Consider learners' translations of mówi as film or cinéma. Due to the similarity in the Polish signifier mówi and the English signifier movie, they incorrectly assigned an English signified (the concept of a movie) to the Polish signifier mówi 'he/she speak'. The outcome of this process was the French signifiers film or cinéma, ultimately incorrect translations. The relation between mówi and movie is purely formal, neither genetic nor semantic. In this case, the similarity between a form in a background language and that in the TL was not immediately useful to the participant. We wonder, however, to what extent learners who develop such working hypotheses, whether accurate or not, may benefit from the actual process of using and accessing their linguistic knowledge stores to the fullest. Following his comment about perceiving similarities across typologically related languages, Ringbom (2007: 8) observes that "it is possible to perceive at least some similarities also across wholly unrelated languages, and all aspects of a related target language can hardly be perceived to be similar". It is the individual forms and functions in the TL input that are analyzed by the learner, not the fact that two languages are typologically related or not. This process of working through one's L2 knowledge stores in an attempt to understand new TL items is clearly unique to L3 acquisition.

\section{Discussion and concluding remarks}

Data reported on in this article provide further evidence for L2s as a determining source of CLI in L3 acquisition. In the present study, we observed our participants' use of L2 knowledge in their performance of tasks in the TL at first exposure to TL Polish and after various periods of exposure. We hypothesized that our learners at this early stage of acquisition would place the Polish negator in front of that which it negates (a verb in this case) in line with findings reported in previous research. We found, however, that learners placed the 
negator in a variety of positions, and in some cases, this placement seemed to be influenced by the structure of clausal negation in one or more of the learner's background languages, even if the background language and the TL were not genetically related. In the case of Russian, a language typologically related to Polish, minimal knowledge appeared to be quite beneficial.

We also hypothesized that learners at the earliest stages of TL acquisition would pay little to no attention to verbal morphology, in line with findings reported in Klein and Perdue (1992) on the structure of the basic variety. Results of a series of grammaticality judgment tests show that in fact some learners, but not all, are sensitive to verbal morphology. Results indicate that some knowledge of Russian, a highly inflected language like Polish, seemed to increase learners' sensitivity to morphological marking.

With regard to oral and written sentence comprehension, we hypothesized that learners would access the elements of their background languages that share features with the TL items in question even in the case of low proficiency levels of both the L2 and the TL. By means of an oral sentence translation test, we found that knowledge of Russian seemed to have a facilitating effect on our learners' translations, especially with increased exposure to Polish. Results of a written sentence translation test taken by first exposure participants showed a slight advantage of Russian as a background language over German but not over other Romance languages. Future research needs to examine carefully not only the words that are understood, but also the formal and functional relations between the TL words and the words in the background languages that may serve as candidates for translation equivalents. This will lead to a better understanding of what constitutes a learner's psychotypology and of the role played by all languages known to the learner in the recognition and learning processes.

Taken together, our findings indicate a beneficial effect of Russian on our learners' ability to accomplish a variety of tasks in Polish. This is not surprising given that Russian is genetically related to Polish and therefore shows similarities on a variety of levels, phonetic, orthographic, morpho-syntactic, and semantic, among others. We argue, however, that language typology alone cannot fully explain the CLI at work in the early stages of TL acquisition. Although our participant sample was not large enough to make strong claims, we observed cases of CLI where the source language was neither the L1 nor the typologically related language (Russian). This is in line with Kellerman's (1983) psychotypology thesis; it is not the genetic relationship per se that influences the learner's processing and production of the TL. It is rather the perceived similarity between certain features in a given word or utterance, such as in Polish mówi 'he/she speaks' and English movie. The words share formal features even though they have no genetic relationship. As in the case of Polish mówi and English movie, the perceived similarity does not help learners find the correct translation. It is interesting to observe, however, that they try. Their reliance on 
formal similarities reflects the work of their psychotypology. Indeed, it is true that genetically related languages have more formal and functional features in common than do unrelated languages. For this reason, typological relatedness may serve, to a certain extent, as a predictor of the degree of psychotypology that may occur.

As De Angelis (2007: 33) points out, "most researchers maintain that CLI is more likely to occur at the early stages of acquisition, when learners' knowledge of the target language is still weak and fragmentary and the need to fill knowledge gaps in the target language is more pressing". Results from the present study confirm this general assumption. At the very beginning of the acquisition of a novel language, adult learners appear to make use of all knowledge available to them, and they do this by means of comparing new information (TL input) with old information (background languages). What learners perceive as similar between languages, regardless of whether or not the languages are typologically related, is what they put to use. This is particularly flagrant at the early stages of TL acquisition. From this perspective, the TL input takes on crucial importance and the learner's perception of how this input relates to his/her prior linguistic knowledge will determine what the learner is able to perceive, comprehend, parse and produce. In other words, it is the perception of what is most similar within the familiar information available that will win out, an observation that needs to be accounted for in models of L2 and L3 acquisition.

The American University of Paris and UMR 7023 (CNRS)

$\langle$ rebrast@aup.fr〉

\section{References}

Bardel, Camilla. 2006. La connaissance d'une langue étrangère romane favorise-t-elle l'acquisition d'une autre langue romane? Influences translinguistiques dans la syntaxe d'une L3. Acquisition et Interaction en Langue Étrangère 24. 149-180.

Bardel, Camilla \& Ylva Falk. 2007. The role of the second language in third language acquisition: The case of Germanic syntax. Second Language Research 23(4). 459-484.

Bardel, Camilla \& Christina Lindqvist. 2007. The role of proficiency and psychotypology in lexical cross-linguistic influence. A study of a multilingual learner of Italian L3. In Marina Chini, Paola Desideri, M. Elena Favilla, \& Gabriele Pallotti (eds.), Atti del VI Congresso Internazionale dell' Associazione Italiana di Linguistica Applicata, Napoli, 9-10 February 2006, 123-145. Perugia: Guerra Editore.

Bernini, Giuliano. 2000. Negative items and negation strategies in nonnative Italian. Studies in Second Language Acquisition 22(3). 399-440.

Carroll, Susanne. 2008. Naming: A first exposure study. Paper presented at the Annual EUROSLA Conference 18, Aix-en-Provence, France, September.

Cenoz, Jasone. 2001. The effect of linguistic distance, L2 status and age on cross-linguistic influence in the third language acquisition. In Jasone Cenoz, Britta Hufeisen, \& Ulrike Jessner 


\section{Rebekah Rast}

(eds.), Cross-linguistic influence in third language acquisition: Psycholinguistic perspectives, 8-20. Clevedon: Multilingual Matters.

Cenoz, Jasone, Britta Hufeisen, \& Ulrike Jessner (eds.). 2001. Cross-linguistic influence in third language acquisition: Psycholinguistic perspectives. Clevedon: Multilingual Matters.

Clahsen, Harold, Jürgen Meisel, \& Manfred Pienemann. 1983. Deutsch als Zweitsprache: Der Spracherwerb ausländischer Arbeiter. Tübingen: Narr.

De Angelis, Gessica. 2005. Interlanguage transfer of function words. Language Learning 55(3). 379-414.

De Angelis, Gessica. 2007. Third or additional language acquisition. Clevedon: Multilingual Matters.

De Angelis, Gessica. 2008. When does an L2 learner become a multilingual learner? Paper presented at the International Conference on Multilingualism, Universitat Jaume I, Castelló, Spain, 16-18 December.

de Bot, Kees. 2004. The Multilingual Lexicon: Modelling Selection and Control. International Journal of Multilingualism 1(1). 17-32.

Dijkstra, Ton. 2003. Lexical processing in bilinguals and multilinguals: The word selection problem. In Jasone Cenoz, Britta Hufeisen, and Ulrike Jessner (eds.), The multilingual lexicon, 11-26. Dordrecht: Kluwer Academic Publishers.

Dijkstra, Ton \& Walter J. B Van Heuven. 1998. The BIA-model and bilingual word recognition. In J. Grainger \& A. Jacobs (eds.), Localist Connectionist Approaches to Human Cognition, 189-225. Hillsdale, NJ: Lawrence Erlbaum.

Giuliano, Patrizia. 2004. La négation dans l'acquisition d'une langue étrangère. Un débat conclu? Bern: Peter Lang.

Hammarberg, Björn (this issue). The languages of the multilingual: Some conceptual and terminological issues.

Hyltenstam, Kenneth. 1977. Implicational patterns in interlanguage syntax variation. Language Learning 27(2). 383-411.

Kellerman, Eric. 1977. Towards a characterization of the strategy of transfer in second language learning. Interlanguage Studies Bulletin 2. 58-145.

Kellerman, Eric. 1979. Transfer and non-transfer: Where we are now. Studies in Second Language Acquisition 2. 37-57.

Kellerman, Eric. 1983. Now you see it, now you don't. In Susan Gass \& Larry Selinker (eds.), Language Transfer in Language Learning, 112-134. Rowley: Newbury House.

Klein, Wolfgang. 1986. Second language acquisition. Cambridge: Cambridge University Press.

Klein, Wolfgang \& Clive Perdue. 1992. Utterance structure: Developing grammars again. Amsterdam: John Benjamins.

Lado, Robert. 1957. Linguistics across cultures: Applied linguistics for language teachers. Ann Arbor: University of Michigan.

Leung, Yan-kit. 2005. L2 vs. L3 initial state: A comparative study of the acquisition of French DPs by Vietnamese monolinguals and Cantonese-English bilinguals. Bilingualism: Language and Cognition 8(1). 39-61.

Lindqvist, Christina. 2009. The use of the L1 and the L2 in French L3: examining cross-linguistic lexemes in multilingual learners' oral production. International Journal of Multilingualism 6(3). 281-297.

MacWhinney, Brian. 2000. The CHILDES project: Tools for analyzing talk, Vol. II: The Database, 3rd ed. Mahwah, NJ: Lawrence Erlbaum Associates.

Meisel, Jürgen. 1997. The acquisition of the syntax of negation in French and German: Contrasting first and second language development. Second Language Research 13(3). 227-263.

Nayak, Nandini, Nina Hansen, Nancy Krueger, \& Barry McLaughlin. 1990. Language-learning strategies in monolingual and multilingual adults. Language Learning 40(2). 221-244.

Perdue, Clive. 2002. Development of L2 Functional Use. In Vivian Cook (ed.), Portraits of the L2 user, 123-142. Clevedon: Multilingual Matters. 
Rast, Rebekah. 2006. Le premier contact avec une nouvelle langue étrangère: Comment s'acquitter d'une tâche de compréhension? Acquisition et Interaction en Langue Étrangère 24. 119-147.

Rast, Rebekah. 2008. Foreign language input: Initial processing. Clevedon: Multilingual Matters. Rast, Rebekah \& Pascale Trévisiol (eds.). 2006. L'acquisition d'une Langue 3. [Special issue]. Acquisition et Interaction en Langue Étrangère 24.

Ringbom, Håkan. 2007. Cross-linguistic similarity in foreign language learning. Clevedon: Multilingual Matters.

Silberstein, Dagmar. 2001. Facteurs interlingues et spécifiques dans l'acquisition non-guidée de la négation en anglais L2. Acquisition et Interaction en Langue Étrangère 14. 25-58.

Trévisiol, Pascale. 2006. Influence translinguistique et alternance codique en français L3: Rôles des L1 et L2 dans la production orale d'apprenants japonais. Acquisition et Interaction en Langue Étrangère 24. 13-43.

Williams, Sarah \& Björn Hammarberg. 2009. Language switches in L3 production: Implications for a polyglot speaking model. In Björn Hammarberg (ed.), Processes in third language acquisition, 28-73. Edinburgh University Press. Originally 1998 in Applied Linguistics 19(3). 295-333. 
Copyright of IRAL: International Review of Applied Linguistics in Language Teaching is the property of De Gruyter and its content may not be copied or emailed to multiple sites or posted to a listserv without the copyright holder's express written permission. However, users may print, download, or email articles for individual use. 